\title{
PENGETAHUAN WANITA TENTANG KANKER PAYUDARA
}

\author{
Women Knowledge About Breast Cancer
}

\author{
Nur Asiah ${ }^{1}$, Diah Arruum ${ }^{2}$, Ellyta Aizar $^{3}$ \\ 1,2,3 Program Studi S1 Keperawatan, Fakultas Keperawatan, Universitas Sumatera Utara \\ Email: asiahnur9478@gmail.com
}

\begin{abstract}
Abstrak
Pengenalan penyakit kanker payudara sangat penting guna menurunkan kasus baru melalui upaya pencegahan dan deteksi dini untuk memudahkan mengenali faktor risiko dan gejala kanker payudara. Kegiatan pengabdian pada masyarakat ini bertujuan untuk mengidentifikasi kemampuan wanita mendeteksi secara dini kanker payudara. Kegiatan pengabdian pada masyarakat ini dilakukan pada bulan Mei sampai dengan Oktiber 2018 di UPT Puskesmas PB Selayang II Medan. Metode pelaksanaan kegiatan pengabdian pada masyarakat ini dimulai dengan mengukur tingkat pengetahuan kader dan masyarakat tentang kanker payudara, dilanjutkan dengan pemberian materi (konseling) tentang kanker payudara dan cara SADARI. Hasil penyebaran instrumen pengetahuan wanita di wilayah kerja puskesmas tentang kanker payudara diperoleh bahwa 30 orang wanita $(60 \%)$ memiliki pengetahuan yang kurang tentang kanker payudara. Untuk itu perlu dilakukan tindak lanjut untuk melatih para kader dan mengajarkan kepada masyarakat agar mampu mengenal dan menilai faktor risiko secara berkelanjutan selanjutnya diajarkan bagaimana teknik SADARI dan pada tahap lanjut perlu dilakukan pemeriksaan payudara dengan menggunakan breasligh.
\end{abstract}

Kata kunci: pengetahuan, wanita, kanker payudara

\begin{abstract}
Introduction about breast cancer is very important in order to decrease new cases through the efforts of prevention and early detection to make it easier to recognize the risk factors and symptoms of breast cancer. This community service activities aiming to identify women's ability to detect early breast cancer. This community service activities performed on May to October 2018 in the UPT PUSKESMAS PB SELAYANG II Medan. The method of implementation of community service activities started by measuring the level of knowledge about society and the cadre of breast cancer, followed by the giving of material (counseling) about breast cancer by SADARI. Results dissemination instruments of knowledge work in the area of women's health centers on breast cancer obtained that 30 women $(60 \%)$ have less knowledge about breast cancer. For it to do a follow-up to train cadres and taught to the community to recognise and assess the risk factors in a sustainable way next taught how about SADARI techniques and further stages need to be done breast exam by using breasligh.
\end{abstract}

Keywords: knowledge, women, breast cancer

\section{PENDAHULUAN}

Kanker payudara merupakan penyakit keganasan akibat pertumbuhan dan penyebaran sel yang abnormal. Insiden kanker payudara lebih rendah pada negaranegara yang sedang berkembang dibandingkan dengan negara-negara yang sudah maju (Parkway Cancer Centre, 2011). Kanker payudara yang diketahui sejak dini memiliki kemungkinan untuk mendapatkan penanganan yang lebih baik. Kebanyakan masyarakat yang datang ke rumah sakit sudah mengalami kanker payudara stadium lanjut. Hal inilah yang memicu tingginya angka kematian akibat kanker payudara semakin meningkat. Tindakan deteksi dini perlu dilakukan agar dapat mendeteksi dini sel-sel abnormal yang ada didalam tubuh agar dapat ditemukan sebelum berkembang menjadi kanker yang mematikan. Sayangnya masyarakat kurang perhatian terhadap diri sendiri, merasa malu untuk mengungkapkan yang dialami serta tidak mencari informasi mengenai kanker payudara dan cara mendeteksinya(American Cancer Society, 2011, Sari dkk, 2016).

Menurut data World Health Organization(2012)menunjukkan bahwa $78 \%$ kanker payudara terjadi pada wanita usia 50 tahun ke atas, sedangkan $6 \%$ 
diantaranya kurang dari 40 tahun. Pada tahun 2008, 48.034 orang di Inggris didiagnosis kanker payudara dan 11.728 orang meninggal karenakanker payudara pada tahun 2009 (Cancer Research UK, 2011). Kasus tertinggi di dunia pada tahun 2008 terdapat di Perancis dengan tingkat kejadian sebesar $99,7 \%$ atau sebanyak 51.012 kasus (ChartBin, 2011). Data dariAmerican Cancer Society (2013) telah menghitung bahwa di Amerika, terdapat64.640 kasus kanker payudara. Sekitar 39.620 wanita meninggal di dunia setiap tahunnya karena kanker payudara.

Meskipun belum ada penyebab spesifik kanker payudara, Menurut American Cancer Society (2012) faktor reproduksi, usia, penggunaan hormon, penyakit fibrokistik, obesitas, adanya riwayat keluarga danfaktor genetik merupakan beberapa faktor risiko terjadinya kanker payudara. Hal ini menunjukkan bahwa semua wanita dianggap berisiko untuk mengalami kanker payudara selama hidupnya. Namun, pencegahan dan deteksi dini bisa dilakukan agar tidak memberi kesempatan sel kanker untuk menyebar.

Berdasarkan uraian tersebut maka perlu dilakukan suatu kegiatan pengabdian masyarakat untuk melakukan deteksi dini terjadinya kanker payudara.

Permasalahan Mitra

Berdasarkan Hasil Survei Mawas Diri yang dilakukan oleh UPT Puskesmas PB Selayang II Medan dan penentuan prioritas masalah kesehatan dengan menggunakan metode USG diperoleh skor 125 dan melalui sistem skoring di Musyawarah Masyarakat Desa masih kurangnya pemahaman masyarakat tentang kesehatan dan masyarakat sangat memerlukan penyuluhan kesehatan. Selama ini masyarakat belum pernah mendapatkan informasi tentang kanker payudara, cara deteksi dini kanker payudara melalui pemeriksaan payudara sendiri (SADARI) dan tidak mengetahui bagaimana cara mendeteksi faktor risiko kanker payudara.

\section{METODE}

Kegiatan pengabdian pada masyarakat ini dilakukan pada buklan Mei sampai dengan Oktober 2018 di UPT Puskesmas PB Selayang II Medan. Metode pelaksanaan kegiatan pengabdian pada masyarakat ini dimulai dengan mengukur tingkat pengetahuan kader dan masyarakat tentang kanker payudara, dilanjutkan dengan pemberian materi (konseling) tentang kanker payudara dan cara SADARI. Kegiatan berikutnya adalah melatih kader tentang cara mengenal/ mengidentifikasi faktor risiko kanker payudara. Setiap tahapan kegiatan pengabdian kepada masyarakat ini dilakukan oleh tim.

\section{HASIL}

Hasil penyebaran instrumen tentang karakteristik wanita di UPT Puskesmas PB Selayang 2 Medan diperoleh mayoritas berusia 36-40 tahun (24\%), suku Jawa 25 orang $(50 \%)$, beragama Islam sebanyak 40 orang $(80 \%)$, sudah menikah sebanyyak 41 orang $(82 \%)$, berpendidikan SMA sebanyak 40 orang $(80 \%)$, sebanyak 30 orang $(60 \%)$ tidak pernah mendapat infromasi tentang kanker payudara, menarche pada usia 13 tahun sebanyak 22 orang (44\%) dan terdapat 2 orang (4\%) yang mempunyai riwayat keluarga dengan kanker payudara.penjabaran hasil penyebaran kuisioner dapat dilihat pada tabel berikut.

Tabel 1. Distribusi frekuensi karakteristik ibu di UPT Puskesmas PB Selayang 2 Medan

\begin{tabular}{lcc}
\hline Karakteristik & Frekuensi & $\%$ \\
\hline Usia (tahun) & 2 & 4 \\
$20-25$ & 4 & 8 \\
$26-30$ & 8 & 16 \\
$31-35$ & 12 & 24 \\
$36-40$ & 10 & 20 \\
$41-45$ & 8 & 16 \\
$46-50$ & 6 & 12 \\
$51-60$ &
\end{tabular}

$\begin{array}{lcc}\text { Suku } & & \\ \text { Jawa } & 25 & 50 \\ \text { Batak } & 8 & 16 \\ \text { Melayu } & 5 & 10 \\ \text { Sunda } & 5 & 10 \\ \text { Aceh } & 2 & 4 \\ \text { Padang } & 5 & 10\end{array}$




\begin{tabular}{|c|c|c|}
\hline \multicolumn{3}{|l|}{ Agama } \\
\hline Islam & 40 & 80 \\
\hline Kristen & 6 & 12 \\
\hline Katolik & 4 & 8 \\
\hline \multicolumn{3}{|l|}{$\begin{array}{l}\text { Status } \\
\text { Perkawinan }\end{array}$} \\
\hline Belum Menikah & 6 & 12 \\
\hline Menikah & 41 & 82 \\
\hline Janda & 3 & 6 \\
\hline \multicolumn{3}{|l|}{ Pendidikan } \\
\hline SD & 1 & 2 \\
\hline SMP & 7 & 14 \\
\hline SMA & 40 & 80 \\
\hline \multicolumn{3}{|l|}{ Perguruan } \\
\hline Tinggi & 2 & 4 \\
\hline \multicolumn{3}{|l|}{$\begin{array}{l}\text { Riwayat } \\
\text { mendapat } \\
\text { informasi }\end{array}$} \\
\hline Pernah & 20 & 40 \\
\hline Tidak pernah & 30 & 60 \\
\hline \multicolumn{3}{|l|}{$\begin{array}{l}\text { Usia Menarche } \\
\text { (tahun) }\end{array}$} \\
\hline 12 & 18 & 35 \\
\hline 13 & 22 & 44 \\
\hline 14 & 10 & 2 \\
\hline \multicolumn{3}{|l|}{$\begin{array}{l}\text { Riwayat } \\
\text { Keluarga } \\
\text { dengan kanker } \\
\text { payudara }\end{array}$} \\
\hline Ada & 2 & 4 \\
\hline Tidak ada & 48 & 96 \\
\hline
\end{tabular}

Hasil penyebaran instrumen tentang pengetahuan wanita di UPT Puskesmas PB Selayang 2 Medan tentang kanker payudara diperoleh mayoritas 30 orang $(60 \%)$ tidak mengetahui tentang kanker payudara. Hasil penyebaran instrument tersebuit dijabarkan pada tabel berikut:

Tabel 2. Distribusi frekuensi pengetahuan wanita di UPT Puskesmas PB Selayang 2 Medan tentang kanker payudara

\begin{tabular}{lcc}
\hline Pengetahuan & $\mathrm{f}$ & $\%$ \\
\hline Kurang & 30 & 60 \\
Baik & 20 & 40 \\
\hline
\end{tabular}

\section{PEMBAHASAN}

Hasil penyebaran kuisioner yang telah dilakukan menunjukkan bahwa pengetahuan wanita di UPT Puskesmas PB Selayang 2 Medan secara umum adalah kurang (60\%). Hal ini dikarenakan masyarakat tidak pernah mendapatkan informasi tentang kanker payudara sebelumnya, dilihat dari 48 responden menyatakan tidak pernah mendapatkan informasi tentang kanker payudara khususnya dari petugas kesehatan setempat. Informasi yang diperoleh responden tentang kanker payudara akan sangat mendukung pengetahuan responden terhadap deteksi dini kanker payudara. Menurut pendapat Notoatmodjo (2008) bahwa semakin banyak memperoleh informasi maka dapat mempengaruhi atau menambah pengetahuan seseorang dan dengan pengetahuan tersebut dapat mempengaruhi perilaku seseorang sesuai dengan pengetahuan yang dimilikinya.

Menurut Nanda (2005) faktor yang terkait dengan kurangnya pengetahuan adalah kurang terpapar informasi, kurang daya ingat atau hapalan, salah menafsirkan informasi, keterbatasan kognitif, kurang minat untuk belajar dan tidak familiar terhadap sumber informasi.

Pengetahuan merupakan hasil dari tahu, dan ini terjadi setelah orang melakukan penginderaan suatu objek tertentu. Pengindraan terjadi melalui pancaindra manusia, yakni indra penglihatan, pendengaran, penciuman, rasa dan raba. Faktor yang mempengaruhi pengetahuan seseorang adalah, faktor internal meliputi pendidikan, persepsi, motivasi juga pengalaman dan fakor eksternal meliputi informasi, sosial budaya dan lingkungan (Notoatmodjo,2012). Pengetahuan seseorang dipengaruhi oleh pendidikan. Semakin tinggi pendidikan seseorang maka semakin baik pula pengetahuannya (Azwar, 2007).

Sebanyak 20 orang responden $(40 \%)$ pada kegiatan ini adalah kader yang bekerja di wilayyah kerja UPT Puskesmas PB Selayang 2 Medan. Berdasarkan hasil uji silang data diperoleh selurih kader yang terlibat dalam kegiatan ini sudah pernah mendapat informasi tentang kanker payudara, namun mereka belum pernah 
mengetahuoi bagaimana cara mengenal faktor risiko dan cara menilai fakotr risiko kanker payudara. Hal ini disebebkan karena kader tersebut belum pernah mendapat pelatihan tentang cara mengenal dan menilai faktor risiko kanker payudara. Kurangnya informasi tersebut akan mempengaruhi kemampuan kader dalam memberikan penjelasan kepada masyarakat.

\section{KESIMPULAN DAN SARAN}

Berdasarkan hasil penyebaran kuisioner pengetahuan wanita tentang kanker payudra di UPT Puskesmas PB Selayang 2 Medan diperoleh mayoritas memiliki pengetahuan yang kurang. Untuk itu perlu dilakukan tindak lanjut untuk melatih para kader dan mengajarkan kepada masyarakat agar mampu mengenal dan menilai faktor risiko secara berkelanjutan selanjutnya diajarkan bagaimana teknik SADARI dan pada tahap lanjut perlu dilakukan pemeriksaan payudara dengan menggunakan breasligh.

\section{DAFTAR PUSTAKA}

American Cancer Society. Breast Cancer Facts \& Figures 2015-2016.

Bright. K. et.al. 2011. The role of health sustem factors in delaying final diagnosis and treatment of breast cancer in Mexico City, Mexico. Elsevier
Kementerian Kesehatan RI. 2013. Pedoman Teknis Pengendalian Kanker Payudara dan Kanker Leher Rahim

Kementerian Kesehatan RI. 2015. Situasi Penyakit kanker

Kementerian Kesehatan RI. 2015. Panduan Nasional Penanganan Kanker Payudara

Medicine for Global Health. 2015. Catastrophic health expenditure and 12-month mortality associated with cancer in Southeast Asia: results from a longitudinal study in eight countries. Research Article

Nurleli. P.W, Maneewat. Khomapak. 2014. Patient delay in consulting a medical doctor among Aceh women with breast cancer

The New England Comparative Effectivenes Public Advisory Council. 2014. An Action Guide for Supplemental Cancer Screening for Women with Dense Breasts: Next Steps for Patients, Clinicians, and Insurers

U. S. Department of Health and Human Services Health Resources and Services Administration. 2015. Breast Cancer Screening

Widodo. I. 2014. Clinicopathological Features of Indonesian Breast Cancers with Different Molecular Subtypes. Research Article. 